\title{
Developing reusable components database system for Special vehicles
}

\author{
Hongchao $\mathrm{Wu}^{1, \mathrm{a}}$, Nan $\mathrm{Nan}^{2, \mathrm{~b}}$, Pu Zhao ${ }^{1, \mathrm{c}}$ \\ ${ }^{1}$ China North Vehicle Research Institute, Beijing 100072, China \\ ${ }^{2}$ Jining Polytechnic, Jining 272073, China \\ awhoaelf@sina.com, bouttol@163.com, cpuzhao@noveri.com.cn
}

Keywords: Reusable component, Reuse design, Special vehicles, system development, Database.

\begin{abstract}
The research on the database development of the reusable parts of special vehicles is particularly important for shortening the design cycle and accelerating the development of the product. This paper takes the reuse parts database development as the research background, adopts organization and management platform of PDM, combines product design resources' result process and result information, applies knowledge based management system to reuse the design resource unit in the design resources library organization and management, effectively establishes the mechanism of management of the design resource, and finally maximizes the reuse of design resources, reduces the design cycle and development costs obviously.
\end{abstract}

\section{Introduction}

Reuse parts database is mainly used to solve the problem the selection of overall design process, general arrangement, performance simulation calculation stage, and component parts of the second design reference about heavy vehicles to facilitate the overall designer for design calculation [1].

Database system of the reusable parts adopts organization and management platform of PDM, combines product design resources' result process and result information, applies knowledge based management system to reuse the design resource unit in the design resources library organization and management, and ultimately provides services for reuse [2]. Design resources are the design results of the product design process, the decision process and the knowledge about making the decision. The purpose of reusable database system development is to effectively establish the mechanism of management of the design resource, maximize the reuse of design resources, and finally reduce the design cycle and development costs obviously [3].

This paper takes the reusable component database of special vehicles as the research background, and establishes the reusable model of the product design through the research of the reusable mechanism of the product design resources. On the basis of the model, the management technology of the product design resource storehouse is studied, and a reusable design platform is designed and developed.

\section{Architecture design of reusable component system}

The reusable system is the classification management of existing models, components, parts model, file and the attributes to supply reference to the design personnel in the modification design and the new design.

A summary of the design framework of the reusable component library is described as follows:

(1) The reusable parts can be storage according to classification tree structure and the structure can be modified dynamically, and the designer can browse the reusable parts through the structure tree;

(2) Each reusable piece of data structure can be changed, and parameters items can be increased, expanded and deleted;

(3) provide the function of search function, and information can be searched through various simple conditions and combination conditions [4]; 
(4) The model and attribute data of reusable parts can be controlled through privilege management mechanism to guarantee the accuracy and the tightness of data;

(5) The reusable component library has data import and export function, and can be used to export the relevant data into Excel or XML format, or import data into these formats [5].

According to the design framework of reusable parts database, this paper can build the reusable pieces management function module and show as Fig.1.

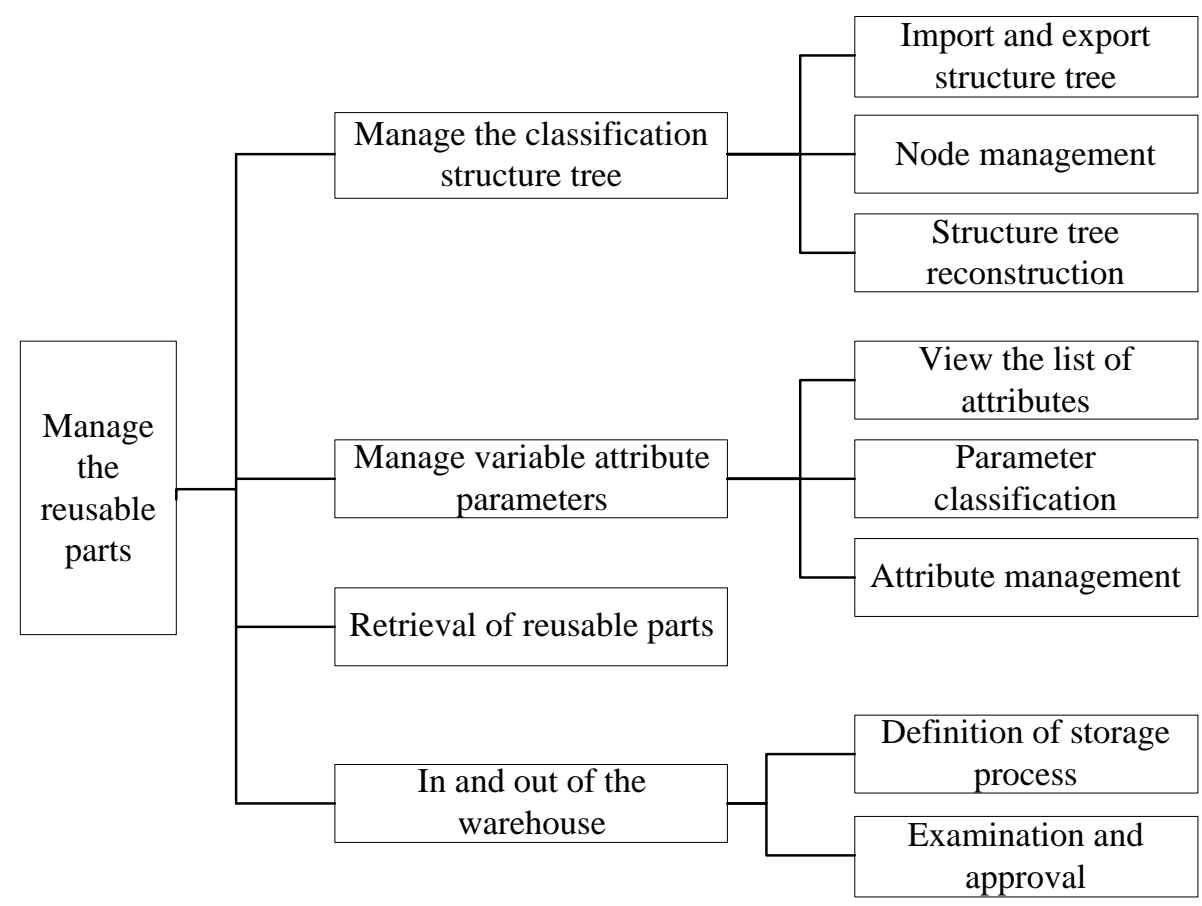

Fig.1 Management function module of reusable component

\section{The correctness and security of reusable pieces of data}

The correctness of reusable component data in this system is mainly guaranteed by the two process of releasing reusable information, as shown in Fig2.

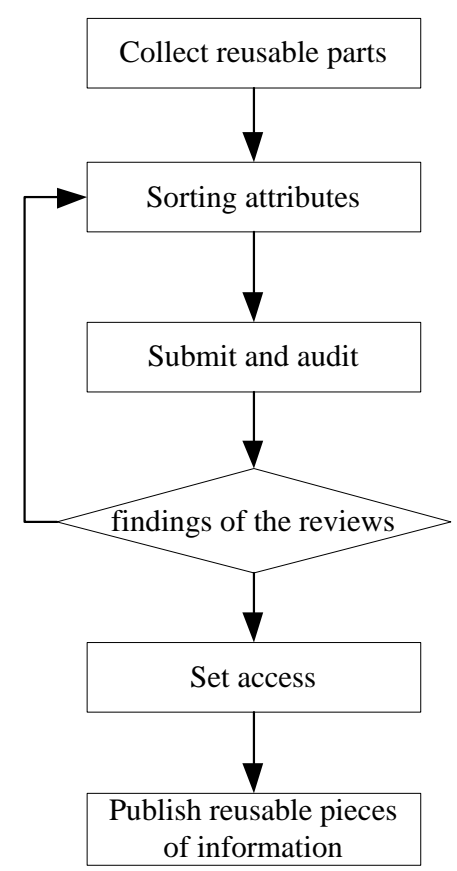

Fig.2 Process of reusable components storage 
On one hand, collect already stereotypes type, components, parts and other reusable parts, collate and verify the reusable parts of the model, data, parameters and other information; on the other hand, auditors need to audit the correctness of the data. The security of reusable parts is mainly through the establishment of a privilege control mechanism, and set up the permissions and download permissions of the reusable parts for different persons.

\section{Development and implementation of reusable component system}

Reusable parts library mainly has five functions, the organization structure, reusable attribute management, reusable pieces management, approval management and reusable search. Designers can not only rebuild a reusable library, but also upload and edit the data in the project

\subsection{Implementation of organization structure.}

The organization tree can project the structure and the structure of the project so that the structure can be clearly added to the project, as shown in Fig.3.

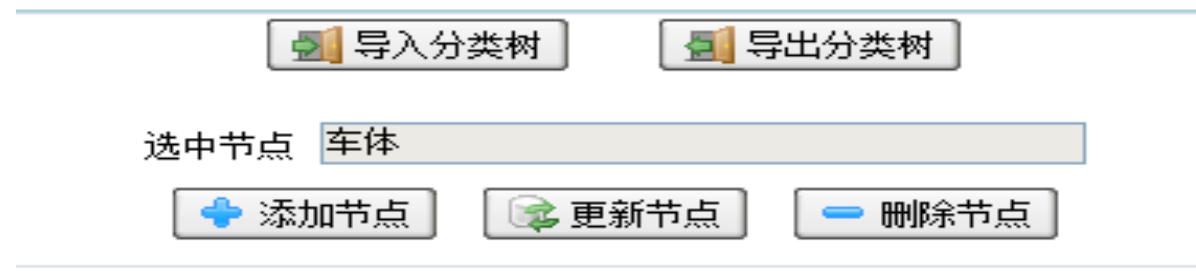

Fig.3

\subsection{Implementation of reusable attribute management.}

Reusable attribute contains names, classes, units, types, and priorities, and the type includes parameters, text and file of these types, as shown in Fig 4.

\begin{tabular}{|c|c|c|}
\hline 名称 车宽 & 类别 基本殿性 & T \\
\hline 度里单位 米 & 类型 虐閶 & $\checkmark$ \\
\hline 优先级 1 & & \\
\hline st增加 & \multicolumn{2}{|c|}{ E保存 } \\
\hline
\end{tabular}

Fig.4

\subsection{Implementation of reusable pieces management.}

The reusable management means that the user can import the export data in batches, and edit, view, delete and download the data, as shown in Fig 5.

\begin{tabular}{|c|c|c|c|c|c|}
\hline \multicolumn{3}{|c|}{ 选中节点车体 } & f 新增 & 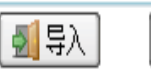 & 息导出 \\
\hline 回名称 & 版本 & 今创建日期 & 今创建人 & $\Rightarrow$ 状态 & 操作 \\
\hline 回车 & 3.0 & 2015-04-15 & 管理员 & 待审批 & 查看 更新 \\
\hline 车 & 2.0 & 2015-04-15 & 管理员 & 待审批 & 查看 車新 \\
\hline
\end{tabular}

Fig.5

\subsection{Implementation of approval management.}

People who have the right to approve the data for reusable components, and decide whether the data is scientific, true and valid, as shown in Fig 6. 


\begin{tabular}{|c|c|c|c|c|c|c|c|c|}
\hline \multicolumn{9}{|c|}{ 可重用件入库审批 } \\
\hline 待审非 & 末通过 & 回收站 & & & & & & \\
\hline 名称 & & & 今版本 & 今创建日期 & $\Rightarrow$ 创建人 & 令状态 & 令操作 & $\overrightarrow{4}$ \\
\hline 车 & & & 4.0 & $2015-04-15$ & 管理员 & 待审批 & 查看 & \\
\hline 车 & & & 3.0 & $2015-04-15$ & 管理员 & 待审批 & 查看 & \\
\hline 车 & & & 2.0 & $2015-04-15$ & 管理员 & 待审批 & 查看 & \\
\hline 车 & & & 1.0 & $2015-03-21$ & 管理员 & 待审批 & 查看 & \\
\hline
\end{tabular}

Fig.6

\subsection{Implementation of reusable search.}

Query of reusable components is a commonly used feature, including direct search results in search, advanced retrieval and export results in four parts, as shown in Fig 7.

\begin{tabular}{|c|c|c|c|c|c|c|}
\hline \multicolumn{7}{|c|}{ 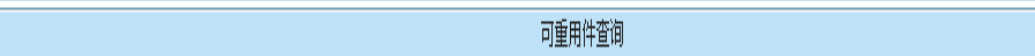 } \\
\hline 车 & 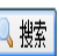 & 结果中撽索 & 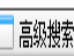 & 国导出蛙果 & & \\
\hline 回嗮 & & & A 顷本 & 创建明期 & 今姐人 & 排 \\
\hline 田车 & & & 5.0 & 2015-04-15 & 管理员 & 鲁看 \\
\hline
\end{tabular}

Fig.7

\section{The correctness and security of reusable pieces of data}

This paper takes the reusable component database of special vehicles as the research background, adopts organization and management platform of PDM, combines product design resources' result process and result information, applies knowledge based management system to reuse the design resource unit in the design resources library organization and management, effectively establishes the mechanism of management of the design resource and ultimately provides services for reuse. Herein we also studies the design platform of reusable parts for special vehicles. Through this platform, designers can effectively establish management of these design resources to assist design, in order to shorten the project period and reduce the development costs of the purpose.

\section{Acknowledgment}

This work is supposed by National Natural Science Foundation of China (Grant No.61304206).

\section{References}

[1]. Hui Tianshu, Li Yushan, Chen Zong ji. Research on Model Reusability in Simulation. Journal of Beijing University of Aeronautics and Astronautics. Vol. 25 (1999) No. 3, p. 329-333.

[2]. Jack P.C. Kleijnen. Verification and validation of simulation models. European Journal of Operational Research Vol. 82 (1995) No. 1, p.145-162.

[3]. QI Feng, Tan jian Rong, et al. Design Resource Reusable Model and Process for Mass Customization. Computer Integrated Manufacturing Systems. Vol. 10 (2004) No. 5, p. 508-512.

[4]. Szykman, Simon, et al. Design repositories: engineering design's new knowledge base. IEEE Intelligent Systems. 2000, p. 48-55.

[5]. Ma Jun, Qi guo Ning, et al. Parts resource reusable modeling and matchingfor rapid response design. Journal of Zhejiang University (Engineering Science). Vol. 42(2004) No. 8, p. 1428-1433. 